Mr. H.'s proposition, I contend, is anatomically incorrect, for we all know that on the right side the subclavian artery is separated from the subclavian and jugular veins by a distinct and strong band of the deep cervical faseia, which is of such resistance, as to prevent any communication of arterial impulse between those vessels. Besides this fascia, the thoracic duct also interferes on the left side. Moreover, how are we to account for similar appearances noticed in the superficial veins of the extremities, in the saphena major, \&c. ? We are told, in the latter instances, to look for other causes than arterial impulse; but will Mr. Hodges enlighten us upon those causes? One word more, and I have done with Mr. Hodges. The experiment of pressing on the subclavian vein I tried, but with a different result from this gentleman. It is true the pulsation was diminished in intensity, though not in regularity; but this, I am satisfied, is to be explained by the arrest given to the circulation in the tube by the pressure of $\mathrm{my}$ finger.

You will doubtless think, that we of the Meath must have more than ordinary opportunities of acquiring medical knowledge, to consider ourselves not unworthy of a notice in such a publication as the LANCET. So it is, I assure you. There is no hospital in Dublin, nor perhaps in Britain, that affords such facilities for the obtaining a thorough knowledge of our arduous profession. The medical officers of this institution are as eminent in their vocation as they are zealous in their instruction to the younger aspirants in the healing art. Hence it is that the utmost cordiality and good feeling have ever subsisted between the student and his medical and surgical instructors, which speaks much for the heads and hearts of both parties. This willingness to give instruction and general courteous demeanour are, I repeat, universally acknowledged amongst us (for it is scarcely worth while to except the irregular attendance of the medical wards in the morning); but I cannot help singling out one individual qui toto capite supereminst omnes. Dr. Wm. Stokes is perhaps known in England only by his stethoscopic publications and researches; but here he is considered one of the first physicians of our metropolis,-uncompromising in his principles, disdaining the slavish and intriguing system so lamentably acted upon bere and elsewhere. His talent and his honesty are his only support, and they fail not. The avowed enemy of all monopoly, his zeal for the advancement of medical knowledge is almost romantic, and only equalled by his ardour in encouraging and assisting the attentive pupil (and him alone) in the prosecution of his laborious studies. I feel that
I should indulge, perhaps, too much on this agreeably fertile subject; but as I am convinced that your columns are as open to the encouragement of medical worth and honesty as they are to the exposure of monopoly and chicane, I shall make no excuse for what I have said. Besides, Mr. Editor, allow me to say, that the profession here do not feel that they are properly represented in the medical periodicals; and it is i to be regretted that the publication from which alone a fair representation of cases is ex. pected, would not devote more of its space to our concerns. It is rumoured that we are to have a LANCET of our own in Dublin upon the above grounds, but I think it would be " no go." I am, Sir,

A Pupil of the Meath Hospital. Dublin, July 12th, 1831.

\section{POISONING BY STRAMONIUM.}

\section{To the Editor of The Lancet.}

Sir,-If you think the following case worth inserting in your weekly periodical you will oblige me by letting it appear. I am, Sir, your obedient servant, $J_{\text {AMES M MSII, }}$

House Surgeon, General Infirmary, Northampton.

CASE.

On Wednesday morning, July 6 , a person applied at the Infirmary for assistance to a patient who had taken by mistake infusion of stramonium for infusion of senna. The particulars are as follows :-

Hannah Gibbs, æt. 36, of delicate habit, swallowed by mistake two teacupsful of the infusion of stramonium for senna tea. About ten minutes afterwards she was seized with giddiness of the head, dimness of sight, and fainting. Her neighbours hearing a noise in her bedroom came to her assistance, and immediately applied to a druggist who sent a powerful emetic which did not produce sickness. Two hours after she had taken the liquid I zaw her, and found her quite insensible ; pupils dilated and insensible to the stimulus of light, the whole muscles of the body convulsed, countenance flushed, and the pulse full, and slower than natural. With the assistance of the infirmary pupils, I immediately used the stomach-pump, and filled the stamach with large quantities of tepid water several times with the best effect. In a few hours afterwards when $I$ went to visit her a second time, I found her down stairs drinking her tea, and quite cheerful. I should have stated that a common enema was administered, which operated freely on the bowels. She has felt no ill effects since, excepting that her sight is not quite so good, and that her head feels lighter, than usual. 